\title{
Thiol/disulphide balance and ischemia modified albumin levels in relapsed brucellosis patients
}

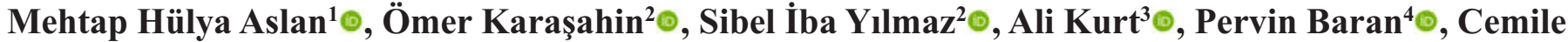 \\ Koca Biçer ${ }^{4} \odot$
}

${ }^{1}$ Department of Clinical Microbiology, Erzurum Regional Training and Research Hospital, Erzurum, Turkey

${ }^{2}$ Department of Infectious Diseases and Clinical Microbiology, Erzurum Regional Training and Research Hospital, Erzurum, Turkey

${ }^{3}$ Department of Clinical Pathology, Erzurum Regional Training and Research Hospital, Erzurum, Turkey

${ }^{4}$ Department of Clinical Biochemistry, Ylldırım Beyazit University Faculty of Medicine, Ankara, Turkey

\begin{abstract}
Objectives: In the study, it was aimed to determine the Thiol/Disulphide profile in patients with relapsed brucellosis and the relationship between Ischemia Modified Albumin (IMA) Levels and Thiol/Disulphide profile.

Methods: Native thiol, Total thiol, Disulphide, Disulphide/Native thiol, Disulphide/Total thiol, IMA levels were measured in forty patients with relapsed brucellosis and healthy control group by using the newly developed method in this cross-sectional study.

Results: There was no statistically significant difference in patients with relapse brucellosis despite the fact that it was lower than total thiol control group $(p>0.05)$. Disulphide was detected high in patients with brucellosis but no statistically significant difference was found $(p>0.05)$. Native thiol and total thiol ratios of disulphide were found to be statistically higher in patients with relapsed brucellosis $(p<0.05)$. In addition, the ratio of native thiol and native thiol to total thiol was statistically lower than the control group $(p<0.05)$. The levels of IMA were statistically significant in patients with relapsed brucellosis compared to the control group $(p<0.05)$. There was a statistically significant positive correlation between IMA values and Disulphide and Disulphide/Native thiol, Disulphide/Total thiol, Native thiol/Total thiol ratios $(r=0.514, r=0.527, r=0.527$, $\mathrm{r}=0.527$; respectively).

Conclusions: It is known that the response of brucellosis treatment can be followed up with oxidative stress markers and it can also be used as a relapse indicator in our study.

Keywords: Relapse brucellosis, thiol/disulphide, ischemia modified albumin
\end{abstract}

B rucellosis is a zoonotic infectious disease that affects half a million people annually and is considered one of the most important problems for public health [1]. Brucella species can grow and survive in macrophages [2]. Oxidative explosion in host macrophages is the primary mechanism controlling intracellular replication of brusella. In addition, in- hibitors of reactive oxygen species have been reported to reduce anti-Brucella activity of macrophages [3].

Therefore, oxidant-antioxidant molecules have been reported to have a very significant role in Brucella endurance and pathogenesis. It is reported that brusellosis may be associated with production of oxygen radicals and the emergence of antioxidant depletion, 
and that oxidative stress plays a role in the patogenesis of brusellosis [4].

Thiols are mercaptans based sulfhydryl residues that play a significant role in the coordination defense network [4]. In the case of oxidative stress, with the oxidation reaction of cysteine residues, thiols oxides and reversible disulfide bonds are formed. Disulphide bond can be reduced again to thiol group. In this way, thiol-disulphide homeostasis occurs [4]. In various diseases such as cerebral ischemia, pulmonary thromboembolism, coronary artery disease, preeclampsi, policystic over syndrome, celiac disease, impaired thiol disulfide balance has been demonstrated [5-8]. Inflammatory cells which get activated through the production of reactive oxygen and nitrogen compounds fight against microbial pathogens that are considered to be causative agents a variety of infectious diseases [9]. For this reason, Thiol-Disulphide homeostasis was evaluted in infectious diseas such as Crimean Kongo Hemorrhagic Fever and tonsillopharyngitis, and a shift to oxidative side of balance was indentified [10]. The ischemia modified albumin (IMA) results from the modification of cobalt binding sites from the $\mathrm{N}$ - terminal end of albumin with the emergence of free radicals in ischemic tissue [11]. This new albumin molecule, which has lost its ability to bind cobalt, has been reported to be an early marker of ischemia. Furthermore, the use of IMA as a marker for sepsis and community- acquired pneumonia associated with oxidative stress and ischemic damage has been reported in the literature $[12,13]$.

In our study, it was aimed to determine the relationship between thiol- disulphideprofile and IMA use as an oxidative stress indicator in patients with relapsed brucellosis.

\section{METHODS}

\section{Study Population}

This cross-sectional coverage consisted of 40 patients with relapsing disease and 40 healthy individuals who had been diagnosed with brucellosis within the last 6 months who applied to infectious diseases polyclinic. The age and gender of the control group were in agreement with the patient group. Those with known infections, inflammatory or chronic diseases and those who smoke or drink alcohol were excluded.

\section{Definition}

Brucella relaps, with or without bacteria, has been recognized as a recurrence of clinical symptoms within the past six months, with an additional increase in previously titrated Wright and 2- mercaptoethanol titers [14].

\section{Sample Collection}

Approval for study was taken from the local ethics committee (Erzurum Regional Training and Research Hospital - Clinical Research Ethics Committee 2016/12-110). Approval forms are signed for all illnesses and healthy control groups. Venous blood samples were collected between 8 and 10 o'clock in the morning after eight hours of fasting, was separated after centrifugation at $1500 \times \mathrm{g}$ for 10 minutes andstored at $-80^{\circ} \mathrm{C}$ before theanalysis. Thiol/Disulphide homeostasis parameters were quantified utilizing the new way developed by Erel and Neselioğlu [15]. Creactive protein (CRP) levels were measured by nephelometric method (Siemens Dade Behring BN II).

\section{Statistical Analysis}

The data were entered into the SPSS 21.0 statistical package program and analyzed using the same package program. Categorical variable from the descriptive data were presented as frequency distributions, and percentile and continuous variables as mean $( \pm)$ standard deviation and median (largest, smallest value). The normality of distribution of continuous variables was tested by Shapiro-Wilk test. The significance of differences between the groups was evaluated using Mann-Whitney U test, Student's t test, and variance analysis where appropriate and Chi-square and Fisher exact tests were used to examine the difference between categorical variables. Spearman correlation analysis was performed to evaluate the relationship between IMA and thioldisülfide parameters. The statistical significance value was accepted as $p<0.05$.

\section{RESULTS}

Forty brucellosis patients and 40 healthy individuals were included in the study. There was no statistically significant difference between the age of the patients included in patient and control group. Demo- 
graphic and laboratory data between the two groups were presented in Table 1. Relapsing brucellosis patients were found to have a significantly higher sedimentation value than healty control group.
No statistically significant difference was found in patients with brucellosis despite the low detection rate compared to the total thiol control group $(p>$ $0.05)$. Disulphide was found high in patients with bru-

Table 1. Demographic characteristics and laboratory parameters of the study groups

\begin{tabular}{|c|c|c|c|}
\hline & Brusellosis $(n=40)$ & Control group $(n=40)$ & $p$ value \\
\hline $\begin{array}{l}\text { Age (year), } \\
\text { median (min-max) }\end{array}$ & $43(16-75)$ & $39.5(18-74)$ & 0.707 \\
\hline Gender (male/female) & $19 / 21$ & $15 / 25$ & 0.131 \\
\hline $\begin{array}{l}\mathrm{CRP}(\mathrm{mg} / \mathrm{dL}) \\
\text { median }(\min -\max )\end{array}$ & $0.55(0.20-16.00)$ & $0.32(0.32-1.98)$ & 0.107 \\
\hline $\begin{array}{l}\text { Sedimentation }(\mathrm{mm} / \mathrm{h}) \text {, } \\
\text { median }(\min -\max )\end{array}$ & $14.0(2.0-41.0)$ & $5.5(2.0-38.0)$ & $<0.001$ \\
\hline $\begin{array}{l}\text { Leukocyte count }\left(\times 10^{3} / \mathrm{L}\right) \text {, } \\
\text { median }(\min -\max )\end{array}$ & $6.65(3.08-22.40)$ & & \\
\hline $\begin{array}{l}\text { Platelet count }\left(\times 10^{3} / \mathrm{L}\right) \text {, } \\
\text { median }(\min -\max )\end{array}$ & $259(95-537)$ & & \\
\hline $\begin{array}{l}\operatorname{ALT}(\mathrm{U} / \mathrm{L}) \\
\text { median (min-max) }\end{array}$ & $27.5(10.0-133.0)$ & & \\
\hline $\begin{array}{l}\operatorname{AST}(\mathrm{U} / \mathrm{L}) \\
\operatorname{median}(\min -\max )\end{array}$ & $24.5(12.0-85.0)$ & & \\
\hline $\begin{array}{l}\text { Creatinine }(\mathrm{mg} / \mathrm{dL}) \\
\text { median }(\min -\max )\end{array}$ & $0.73(0.50-1.18)$ & & \\
\hline $\begin{array}{l}\text { Hemoglobin }(\mathrm{g} / \mathrm{dL}) \\
\text { median (min-max) }\end{array}$ & $14.00(9.40-18.10)$ & & \\
\hline \multicolumn{4}{|l|}{ Previous treatment, n (\%) } \\
\hline Rifampicin + doxycycline & $37(92.5)$ & & \\
\hline $\begin{array}{l}\text { Rifampicin }+ \text { doxycycline }+ \\
\text { aminoglycoside }\end{array}$ & $1(2.5)$ & & \\
\hline Doxycycline + quinolones & $2(5.0)$ & & \\
\hline
\end{tabular}

Table 2. Thiol/disulfide profiles and ischemia-modified albumin levels of the study group

\begin{tabular}{lccc}
\hline & Brusellosis $(\mathbf{n}=\mathbf{4 0})$ & Control group $(\mathbf{n}=\mathbf{4 0})$ & $\boldsymbol{p}$ value \\
\hline IMA & $78.05(71.80-90.50)$ & $75.90(68.50-83.30)$ & $\mathbf{0 . 0 0 3}$ \\
Native thiol $(\mu \mathrm{mol} / \mathrm{L})$ & $280.95(126.70-414.00)$ & $322.05(211.50-390.90)$ & $\mathbf{0 . 0 2 8}$ \\
Total thiol $(\mu \mathrm{mol} / \mathrm{L})$ & $332.35(152.70-496.10)$ & $347.45(232.10-437.50)$ & 0.214 \\
Disulphide $(\mu \mathrm{mol} / \mathrm{L})$ & $20.75(0.80-43.60)$ & $13.50(0.35-30.85)$ & 0.066 \\
Disulphide/Nativethiol $(\%)$ & $7.26(0.22-15.96)$ & $4.85(0.14-10.58)$ & $\mathbf{0 . 0 0 9}$ \\
Disulphide/Total thiol $(\%)$ & $6.34(0.22-12.10)$ & $4.42(0.14-8.74)$ & $\mathbf{0 . 0 0 9}$ \\
Native thiol/Total thiol $(\%)$ & $87.30(75.80-99.56)$ & $91.15(82.53-99.72)$ & $\mathbf{0 . 0 0 9}$ \\
\hline
\end{tabular}

Data were expressed as median (minumum - maximum), IMA = Ischemia modified albumin, 
Table 3. Relations between thiol-disulphide profiles and ischemia-modified albumin levels

\begin{tabular}{lccccccc}
\hline & Native thiol & $\begin{array}{c}\text { Total } \\
\text { Thiol }\end{array}$ & Disulphide & $\begin{array}{c}\text { Disulphide/ } \\
\text { Native thiol }\end{array}$ & $\begin{array}{c}\text { Disulphide/ } \\
\text { Total thiol }\end{array}$ & $\begin{array}{c}\text { Native thiol/ } \\
\text { Total thiol }\end{array}$ & Sedimentation \\
\hline IMA & $\mathrm{r}=0.189$ & $\mathrm{r}=-0.65$ & $\mathbf{r}=\mathbf{0 . 5 1 4}$ & $\mathbf{r}=\mathbf{0 . 5 2 7}$ & $\mathbf{r}=\mathbf{0 . 5 2 7}$ & $\mathbf{r}=\mathbf{0 . 5 2 7}$ & $\mathrm{r}=0.248$ \\
$(\mathrm{n}=80)$ & $\boldsymbol{p}=\mathbf{0 . 0 1 2}$ & $p=0.692$ & $\boldsymbol{p}=\mathbf{0 . 0 0 1}$ & $\boldsymbol{p}<\mathbf{0 . 0 0 1}$ & $\boldsymbol{p}<\mathbf{0 . 0 0 1}$ & $\boldsymbol{p}<\mathbf{0 . 0 0 1}$ & $p=0.123$ \\
\hline
\end{tabular}

IMA $=$ Ischemia modified albumin

cellosis but no statistically significant difference was detected $(p>0.05)$. The native thiol and total thiol ratios of disulphide were statistically higher in patients with relapsed brucellosis $(p<0.05)$. In addition, the ratio of total thiole to native thiol and native thiol was statistically lower than the control group $(p<0.05)$. IMA levels were found statistically higher in patients with brucellosis than control group $(p<0.05)$ (Table 2 ). There was a statistically significant positive correlation between IMA value and Disulphide and Disulphide/Native Thiol, Disulphide / Total thiol, Native thiol/ Total thiol ratios $(p>0.500, p<0.05)$ (Table 3$)$.

\section{DISCUSSION}

Relaps of brucellosis occurs as an important problem during the treatment. Cellular immunity and treatments provided bacterial elimination; however, chronic and relapsed infections were seen due to the presence of intracellular microorganisms. Previously, Brucella-PCR was used for the detection of Brucella relapse [16]. In our study, it was aimed to determine the thiol/ disulphide profile in patients with relapsed brucellosis and, at the same time to determine the relationship between IMA levels and thiol/ disulfide profile. The mechanism by which Brucella saved itself without being killed in an intercellular fashion was not fully understood. However, it was reported that the main mechanism that controls intracellular replication was the oxidative explosion in host macrophages [3]. The endogenous reactive oxygen compounds of aerobic respiratory metabolism against Brucella strains have been shown to be exogenously produced for both endogenous and anti-Brucella activities of macrophages [3]. Reactive oxygen compounds responsible for oxidative stress was elevated in inflammation leading to cell damage via peroxidation of double -chain fatty, protein and DNA[17]. It was re- ported that this condition is responsible for the pathogenesis of diseases through accompanying the primary disease [18]. There were studies showing that oxidative stress plays a role in the pathogenesis of various bacterial infectious diseases such as Hepatitis C, Influenza, HIV, Sepsis, Crimean Congo Hemorrhagic fever, as well as non-infectious diseases [19-23]. In these cases, oxidant capacity increased and deterioration was observed in antioxidants [19]. In support of this situation, serum antioxidant activity indicators such as total peroxide malondialdehyde, paroxonase and arylesterase in osteomyelitis, tuberculosis, brusellosis and Hepatitis B infections were significantly lower than those in healthy individuals, as shown in literature [4]. Also in previous studies, reduced total antioxidant capacity in Brucella infection has been explained by the depletion of antioxidants as an elevated free radical scavenger [4].

Thiol groups were the main antioxidant components of serum and prevented tissue damage by reacting and neutralizing these molecules with free oxygen radicals and lipid peroxides [10]. Thiols can enter oxidation reactions, convert to the inverse forms called disulfide bonds (-S-S), which can then be converted to thiol groups. Thus thiol-disulfide homeostasis occurs [24]. In a study of thiol-disulfide balance in acute brucellosis, it was reported than an increase in disulfide could be observed without a corresponding decrease in thiol or a decrease in thiol without a corresponding increase in disulfide. In this case, when the ratio of disulfide / thiol was evaluated, it was stated that the healthiest results regarding oxidative stress can be achieved [25]. In our study, the disulphide/total thiol and disulphide /native thiol ratios were found to be statistically higher than those of healthy individuals as Kolgelier et al. [25] found in patients with acute brucellosis. As a result, increased oxidative stress can also be found in relapsed brucellosis patients.

Karaağaç et al. [26] found that after Brucella in- 
fection treatment, oxidant capacity and antioxidant parameters reduced, and antioxidant levels increased. In this study, it has been reported that oxidant-antioxidant balance, which can be achieved by treatment with oxidative stress, may contribute to treatment outcome [26]. In our study, the high ratio of disulfide/thiol suggests that it may contribute to follow-up treatment in terms of relapse development undertreatment.

Oxidative stress-induced conformational change in the N-terminal end of albumin, metabolic ions such as cobalt and copper which tie with the $\mathrm{N}$ - terminal end fail due to conformational change and was called altered albumin-shaped 1schemic modified [12]. IMA was a newly developed marker that increases in ischemic and oxidative stress-related pathological conditions such as myocardial infarction, pulmonary embolism, COPD and cerebrovascular event [27]. In inflammatory diseases, high IMA levels have been shown to be indicative of oxidative stress, together with inflammation and oxidative stress associated with the pathogenesis of these diseases [28]. Furthermore, the use of IMA as a marker in infectious diseases such as sepsis and community-acquired pneumonia associated with oxidative stress and ischemic damage has been reported in the literature. In these diseases, it has been recognized as an important marker of ischemic damage in tissues and organs, helping to identify and quantify oxidative stress [13]. In our study, IMA value was statistically found to be significantly higher in patients with relapsed brucellosis than in healthy subjects. In addition, a moderately strong positive correlation was detected between disulfide/thiol ratios. This moderately strong relationship was used control the accuracy of parameters used as oxidative stress indicators in cases of relapsing brucellosis.

\section{Limitations}

Limitation in our study was firstly not compared with other oxidative stress markers used as an indicator of oxidative stress. Another limitation is that it was performed with a small number of patients.

\section{CONCLUSION}

Thiol/ disulphide balance, previously balance, previously studied in acute brucellosis, has also been shown to be oxidative in our study of relapsing Brucella cases. IMA was higher in the study group than in the control group and correlation with disulphide /thiol ratios was also considered as a sign of increased oxidative stress in relapsed brucellosis cases. Previous studies have shown that brucellosis treatment response can be followed up with oxidative stress markers and in our study; it has been shown that it can also be used as a relapse indicator.

\section{Authors' Contribution}

Study Conception: MHA, CKB, AK; Study Design: ÖK, SIYY, PB; Supervision: MHA, ÖK, AK; Funding: CKB, PB, MHA; Materials: ÖK, SIY, MHA; Data Collection and/or Processing: CKB, ÖK, PB; Statistical Analysis and/or Data Interpretation: ÖK, CKB, SIY; Literature Review: AK, ÖK, CKB; Manuscript Preparation: ÖK, MHA, SIY and Critical Review: $\mathrm{PB}, \mathrm{AK}, \mathrm{MHA}$.

\section{Conflict of interest}

The authors disclosed no conflict of interest during the preparation or publication of this manuscript.

\section{Financing}

The authors disclosed that they did not receive any grant during conduction or writing of this study.

\section{REFERENCES}

1. Pappas G, Papadimitriou P, Akritidis N, Christou L, Tsianos EV. The new global map of human brucellosis. Lancet Infect Dis 2006;6:91-9.

2. DelVecchio VG, Kapatral V, Redkar RJ, Patra G, Mujer C, Los $\mathrm{T}$, et al. The genome sequence of the facultative intracellular pathogen Brucella melitensis. Proc Natl Acad Sci USA 2002;99:443-8.

3. Jiang X, Leonard B, Benson R, Baldwin CL. Macrophage control of Brucella abortus: role of reactive oxygen intermediates and nitric oxide. Cell Immunol 1993;151:309-19.

4. Serefhanoglu K, Taskin A, Turan H, Ergin Timurkaynak F, Arslan H, Erel Ö. Evaluation of oxidative status in patients with brucellosis. Braz J Infect Dis 2009;13:249-51.

5. Kaplan M, Ates I, Yuksel M, Ozin YO, Alisik M, Erel O, et al. Thiol/disulphide homeostasis in celiac disease. World J Gastrointest Pharmacol Ther 2017;8:120-6.

6. Sanrı US, Özsin KK, Toktaş F, Balcı AB, Üstündağ Y, Huysal $\mathrm{K}$, et al. The effect of thiol-disulfide homeostasis in patients undergoing on-pump coronary artery bypass grafting. Turk Gogus 
Kalp Damar Cerrahisi Derg 2019;27:484-92.

7. Topuz M, Kaplan M, Akkus O, Sen O, Yunsel HD, Allahverdiyev $\mathrm{S}$, et al. The prognostic importance of thiol/disulfide homeostasis in patients with acute pulmonary thromboembolism. Am J Emerg Med 2016;34:2315-9.

8. Ivanov AV, Alexandin VV, Paltsyn AA, Nikiforova KA, Virus ED, Luzyanin BP, et al., Plasma low-molecular-weight thiol/disulphide homeostasis as an early indicator of global and focal cerebral ischaemia. Redox Report 2017;22:460-6.

9. Murray HW, Teitelbaum RF. L-arginine-dependent reactive nitrogen intermediates and the antimicrobial effect of activated human mononuclear phagocytes. J Infect Dis 1992;165:513-7.

10. Kara SS, Erel O, Demirdag TB, CuraYayla BC, Gulhan B, Neselioglu S, et al. Alteration of thiol-disulphide homeostasis in acute tonsillopharyngitis. Redox Report 2017;22:205-9.

11. Bar-Or D, Lau E, Winkler JV. A novel assay for cobalt-albumin binding and its potential as a marker for myocardial ischemia-a preliminary report. J Emerg Med 2000;19:311-5.

12. Prashanth A, Anand U. Clinical significance of ischemia modified albumin in critically ill patients with sepsis. Indian J Clin Biochem 2015;30:194-7.

13. Özsin KK, Balci AB, Sanri US, Guvenc O, Yavuz S. Levels of ischemia: modified albumin in patients undergoing on-pump coronary artery bypass. J Coll Physicians Surg Pak 2020;30:5617

14. Roushan MRH, Amiri MJS, Janmohammadi N, Hadad MS, Javanian M, Baiani M, et al. Comparison of the efficacy of gentamicin for 5 days plus doxycycline for 8 weeks versus streptomycin for 2 weeks plus doxycycline for 45 days in the treatment of human brucellosis: a randomized clinical trial. J Antimicrob Chemother 2010;65:1028-35.

15. Erel O, Neselioglu S. A novel and automated assay for thiol/disulphide homeostasis. Clin Biochem 2014;47:326-32.

16. Roushan MRH, Moulana Z, Afshar ZM, Ebrahimpour S. Risk factors for relapse of human brucellosis. Glob J Health Sci 2015;8:77-82.

17. Chambers JC, Haskard DO, Kooner JS. Vascular endothelial function and oxidative stress mechanisms in patients with Behcet's syndrome. J Am Coll Cardiol 2001;37:517-20.

18. Babior BM. Phagocytes and oxidative stress. Am J Med. 2000;109:33-44.

19. Tufan ZK, Hasanoglu I, Kolgelier S, Alisik M, Ergin M, Yilmaz GR, et al. A retrospective controlled study of thiol disulfide homeostasis as a novel marker in Crimean Congo hemorrhagic fever. Redox Report 2017;22:241-5.

20. Horoz M, Bolukbas C, Bolukbas FF, Aslan M, Koylu AO, Selek $\mathrm{S}$, et al. Oxidative stress in hepatitis $\mathrm{C}$ infected end-stage renal disease subjects. BMC Infect Dis 2006;6:114.

21. Draganov D, Teiber J, Watson C, Bisgaier C, Nemzek J, Remick S, et al. PON1 and oxidative stress in human sepsis and an animal model of sepsis. Adv Exp Med Biol 2010;660:89-97. 22. Bayraktar N, Kilic S, Bayraktar MR, Aksoy N. Lipid peroxidation and antioxidant enzyme activities in cancerous bladder tissue and their relation with bacterial infection: a controlled clinical study. J Clin Lab Anal 2010;24:25-30.

23. Young I, Woodside J. Antioxidants in health and disease. J Clin Pathol 2001;54:176-86.

24. Ghezzi P, Bonetto V, Fratelli M. Thiol-disulfide balance: from the concept of oxidative stress to that of redox regulation. Antioxid Redox Signal 2005;7:964-72.

25. Kolgelier S, Ergin M, Demir LS, Inkaya AC, Aktug Demir $\mathrm{N}$, Alisik M, et al. Impaired thiol-disulfide balance in acute brucellosis. Jpn J Infect Dis 2017;70:258-62.

26. Karaagac L, Koruk ST, Koruk I, Aksoy N. Decreasing oxidative stress in response to treatment in patients with brucellosis: could it be used to monitor treatment? Int J Infect Dis 2011;15:346-9.

27. Gunduz A, Turedi S, Mentese A, Altunayoglu V, Turan I, Karahan SC, et al. Ischemia-modified albumin levels in cerebrovascular accidents. Am J Emerg Med 2008;26:874-8.

28. Guntas G, Sahin A, Duran S, Kahraman R, Duran I, Sonmez $\mathrm{C}$, et al. Evaluation of ischemia-modified albumin in patients with inflammatory bowel disease. Clin Lab 2017;63:341-7. 